\title{
NOTAS SOBRE AS FORMAS DE APROPRIAÇÃO DOS RESÍDUOS SÓLIDOS URBANOS: \\ PENSANDO A PARTIR DOS DOCUMENTÁRIOS BOCA DE LIXO E LIXO EXTRAORDINÁRIO
}

\author{
WELKSON PIRES
}

\begin{abstract}
RESUMO
0 célere crescimento das grandes cidades e a consequente expansão do mercado consumidor urbano, aliados às práticas culturais de caráter consumista, em certa medida impulsionadas pela obsolescência programada dos produtos, conduzem à produção exponencial de resíduos. 0 presente artigo se volta justamente à conjuntura dessa produção de resíduos urbanos, focalizando alguns dos sujeitos aí envolvidos e certas formas de apropriação desses resíduos. Para isso, apoiamo-nos em dois documentários, Boca de Lixo e Lixo Extraordinário, que voltam suas lentes para dois depósitos de resíduos urbanos, os quais se localizavam na Região Metropolitana do Rio de Janeiro. No decorrer do trabalho, duas figuras são colocadas em evidência, o catador de resíduos e 0 artista plástico, cujo ponto em comum é, precisamente, o fato de ambos ressignificarem e transformarem os restos das nossas sociedades consumistas em materiais dotados, respectivamente, de valor de uso - quando se destinam à sobrevivência de sujeitos, sendo restituídos de sua função original ou destinados à reciclagem - ou valor artístico - quando são apropriados pelo artista na constituição de obras de arte.
\end{abstract}

\section{PALAVRAS-CHAVE \\ Resíduos Urbanos; Catador de Lixo; Artista Plástico. \\ NOTES ON THE APPROPRIATION FORMS OF URBAN WASTE: THINKING FROM THE DOCUMENTARIES BOCA DE LIXO AND LIXO EXTRAORDINÁRIO}

\section{ABSTRACT}

The rapid growth of large cities and the consequent expansion of the urban consumer market, coupled with the consumerist cultural practices, to a certain extent driven by the programmed obsolescence of products, lead to exponential production of waste. This article turns to the conjuncture of urban waste production, focusing on some of the subjects involved therein and certain forms of waste ownership. In this regard, was taken as reference two documentaries, Boca de Lixo and Lixo Extraordinário, which highlight two landfills, located formerly in the metropolitan area of Rio de Janeiro. In the course of study, two figures will be put in evidence, the waste collector and the plastic artist, whose common point is precisely the fact that both resignify and transform the remains of our consumerist societies into materials endowed with, respectively, use value - when they are destined for the survival of individuals, being restored in their original function or destined for recycling - or artistic value - when they are appropriated by the artist in the constitution of works of art.

KEYWORDS

Urban Waste; Waste Collector; Plastic Artist.

NOTES SUR LES FORMES D'APPROPRIATION DES DÉCHETS SOLIDES URBAINS: RÉFLEXION À PARTIR DES DOCUMENTAIRES BOCA DE LIXO ET LIXO ETRAORDINÁRIO

1 Professor Adjunto do Instituto de Ciências Sociais da UFAL. 


\section{RÉSUMÉ}

La croissance rapide des grandes villes et, par conséquent, l'expansion du marché consommateur urbaine, alliés aux pratiques culturelles consuméristes, dans une certaine mesure, entraînés par l'obsolescence programmée des produits, conduisent à la production exponentielle de déchets. Cet article se concentre sur la conjoncture de cette production de déchets urbains, en mettant l'accent sur certains sujets impliqués dans ce processus et sur certaines formes d'appropriation des déchets. Pour cela, nous comptons sur deux documentaires, Boca de Lixo et Lixo Extraordinário, qui dirigent leurs lentilles vers deux décharges, autrefois situés dans la région métropolitaine de Rio de Janeiro. Au cours de l'article, deux figure sont mis en évidence, le ramasseur de déchets et l'artiste plasticien, dont le point commun est précisément le fait qu'ils redéfinissent et transforment les restes de nos sociétés consuméristes en matériaux dotés, respectivement, de valeur d'usage - lorsqu'ils sont destinés à la survie des sujets, soit par restitution de sa fonction d'origine, soit par sa destination pour le recyclage - et de valeur artistique - quand ils sont appropriés par l'artiste dans la constitution des œuvres d'art.

\section{MOTS CLÉS}

Déchets Urbains; Ramasseur de Déchets; Artiste Plasticien.

\section{NOTAS SOBRE LAS FORMAS DE APROPIACIÓN DE LOS DESECHOS SÓLIDOS URBANOS: PENSANDO A PARTIR DE LOS DOCUMENTALES BOCA DE LIXO Y LIXO EXTRAORDINÁRIO}

\section{RESUMEN}

El rápido crecimiento de las grandes ciudades y la consiguiente expansión del mercado consumidor urbano, aliados a las prácticas culturales de carácter consumista, en cierta medida impulsadas por la obsolescencia programada de los productos, conduce a la producción exponencial de desechos. El presente artículo se centra justamente en la coyuntura de esa producción de desechos urbanos, enfocando algunos de los sujetos allí involucrados y ciertas formas de apropiación de esos desechos. Para ello, nos apoyamos en dos documentales, Boca de Lixo y Lixo Extraordinário, que dirigen sus lentes hacia dos vertederos de desechos urbanos, los cuales se ubicaban en la Región Metropolitana de Rio de Janeiro. En el transcurso del artículo, dos figuras se ponen en evidencia, el recolector de basura y el artista plástico, cuyo punto en común es precisamente el hecho de que ambos resignifican y transforman los restos de nuestras sociedades consumistas en materiales dotados, respectivamente, de valor de uso - cuando se destinan a la supervivencia de sujetos, siendo restituidos de su función original o destinados al reciclaje - o valor artístico - cuando son apropiados por el artista en la constitución de obras de arte. 


\section{INTRODUÇÃO: DELIMITANDO O PROBLEMA DE PESQUISA}

O célere crescimento das grandes cidades e a consequente expansão do mercado consumidor urbano, aliados às práticas culturais de caráter consumista, em certa medida impulsionadas pela obsolescência programada dos produtos, conduzem à produção exponencial de resíduos. Em paralelo a esse fenômeno, emerge e se dissemina, como parte intrínseca do ciclo produtivo de nossa economia capitalista, o trabalho precário e marginal da catação de resíduos. Enquanto uns consomem até produzir resíduos em excesso, outros vivem dessa excessiva produção de resíduos: de um lado, encontram-se as classes abastadas e seus desperdícios; de outro, acham-se os catadores de resíduos, desprovidos de qualquer poder aquisitivo, que sobrevivem dos restos oriundos das práticas consumistas daquelas classes. Tendo em vista esse contexto, podemos dizer que os resíduos tendem a assumir dois possíveis significados, a saber: podem apresentar-se como algo inútil, desprezível, sendo encarado, por vezes, enquanto um perigo à saúde e ao bem-estar humano; ou serem considerados uma fonte de subsistência.

Diante dessa realidade, o presente artigo se propõe a explorar a conjuntura da produção dos resíduos urbanos, buscando compreender as diferentes visões que se desenvolvem acerca deles. O principal pressuposto que nos norteia é o de que a condição de resíduo não pode ser percebida como o estado final de um objeto de consumo: o objeto que certos sujeitos relegaram à condição de lixo, por considerá-lo inútil, pode vir a ser, posteriormente, restituído à suas funções originais ou mesmo ganhar nova funcionalidade e outros significados quando apropriado por outros sujeitos. No que concerne a esse último processo de significação, duas figuras se sobressaem. A primeira é a do catador de resíduos, sujeito marginalizado pelas classes dominantes, destituído de uma condição social digna, que tira seu sustento da catação de resíduos, apropriando-se do que foi descartado, seja restituindo-lhe suas funções originais, seja vendendo-o como material reciclável. A outra figura, cuja legitimidade no complexo social normalmente não é posta em dúvida, sendo reconhecida e exaltada em suas práticas, é a do artista plástico, sujeito que, através de sua arte, eleva os resíduos de uma condição desprezível à posição de objeto de contemplação.

No decorrer de nosso trabalho, serão, precisamente, essas duas figuras que colocaremos em evidência, o catador de resíduos e o artista plástico, cujo ponto em comum é o fato de ambos ressignificarem e transformarem os restos das nossas sociedades consumistas em materiais dotados, respectivamente, de valor de uso - quando se destinam à sobrevivência de sujeitos, sendo restituídos à sua função original ou destinados à reciclagem - ou valor artístico - quando são apropriados pelo artista na constituição de obras de arte.

A fim de compor uma imagem que nos possibilite uma aproximação em relação às diversas formas de apropriação dos resíduos urbanos e aos sujeitos envolvidos nesses 
processos, apoiamo-nos em dados extraídos, a partir do método da análise documental ${ }^{2}$, de duas produções fílmicas do gênero documentário que voltaram suas lentes para dois depósitos de resíduos urbanos, os quais se localizavam na Região Metropolitana do Rio de Janeiro3:

1) Boca de Lixo (1993), dirigido por Eduardo Coutinho, mostra a realidade dos catadores de resíduos que atuavam no Vazadouro de Itaoca, município de São Gonçalo ${ }^{4}$. Sendo basicamente composto por entrevistas realizadas junto a sujeitos que vivem da catação de resíduos, tal documentário evidencia a situação de vida dessas pessoas e as suas precárias condições de trabalho;

2) Lixo Extraordinário (2011), dirigido por Lucy Walker, centra-se sobre o trabalho do artista plástico Vik Muniz, precisamente durante a realização de seu projeto "Retratos do Lixo". Esse consistia, basicamente, na utilização de refugo no processo de composição de fotografias que buscavam retratar a realidade dos catadores de resíduos. O local escolhido para o desenvolvimento desse trabalho foi o Aterro Sanitário de Jardim Gramacho, o qual se localizava no município de Duque de Caxias. Além do processo de trabalho do referido artista plástico, tal documentário também focalizou a vida dos sujeitos que vivem da catação de resíduos nessa localidade.

\title{
DO LUXO AO LIXO: O CONSUMO COMO FÁBRICA DE RESÍDUOS
}

\begin{abstract}
${ }^{2}$ Partimos do pressuposto metodológico de que os filmes do gênero documentário se configuram como documentos que nos permitem acessar certas realidades, favorecem a observação de indivíduos e das situações nas quais se inserem, oferecendo-nos subsídios para a compreensão de certos comportamentos, relações e contextos sociais. Considerando que documentos dessa natureza se constituem como fontes secundárias de dados e que, por isso, apresentam informações sobre a realidade que podem se mostrar limitadas para os objetivos de uma pesquisa em decorrência do enquadramento e dos processos seletivos de quem os produziu, articulamos os dados extraídos dos documentários selecionados com informações mais gerais provenientes de outras fontes, sempre que isso se fez possível e necessário. Especificamente no que diz respeito ao processo analítico dos documentários selecionados, ele se deu em quatro etapas: 1) assistência integral dos filmes; 2) seleção dos trechos, cujos elementos pudessem nos fornecem subsídios para a compreensão do nosso problema de pesquisa; 3) transcrição das falas dos sujeitos focalizados, descrição de suas condições e das situações em que se encontravam; 4) busca de padrões que nos possibilitassem responder o problema de pesquisa.
\end{abstract}

3 Ambos os "lixões", o vazadouro de Itaoca e o Aterro Sanitário de Jardim Gramacho, que são enfocados, respectivamente, nos documentários Boca de Lixo e Lixo Extraordinário, tiveram suas atividades extintas no primeiro semestre de 2012 de modo a atender a Lei $n^{\circ}$ 12.305, de 02 de agosto de 2010, que instituiu a Política Nacional de Resíduos Sólidos.

${ }^{4}$ Tendo em vista que, em sua maioria, os "lixões" se apresentam como espaços pouco ou nada organizados em termos administrativos, há poucas informações concernentes ao seu funcionamento. Também são bastante imprecisas e, por vezes, inexistentes as informações sobre os catadores que atuam nos "lixões", principalmente quando esses não se encontram vinculados a algum tipo de associação/cooperativa. Dito isso, ressaltamos que as informações, que são apresentadas neste trabalho, acerca do Vazadouro de Itaoca e do Aterro Sanitário de Jardim Gramacho são, em sua totalidade, extraídas dos documentários selecionados e, por isso mesmo, são bastante limitadas. 
Dentre as diversas cidades descritas por ítalo Calvino, em seu romance As cidades invisiveis, Leônia é aquela que melhor caracteriza o aspecto consumista das grandes metrópoles modernas. Seus habitantes nutrem um desejo, nunca saciado, pelo novo e diferente: eles acordam "todas as manhãs em lençóis frescos", lavam-se "com sabonetes recém-tirados da embalagem", vestem "roupões novíssimos", extraem "das mais avançadas geladeiras latas ainda intatas, escutando as últimas lengalengas do último modelo de rádio" (CALVINO, 2005, p. 105). Essa imagem é uma caricatura dos consumidores contemporâneos, os quais estão sempre prontos a adquirir novos produtos que thes ofereçam novas promessas de satisfação para as suas diversas necessidades, desde aquelas mais elementares, relacionadas a subsistência física, passando por aquelas concernentes à inserção, visibilidade e posicionamento do sujeito na sociedade, até aquelas necessidades de caráter mais imaterial, que se referem, por exemplo, ao desenvolvimento da personalidade e à fruição estética.

Neste ímpeto consumista, há implicitamente uma inversão na relação ontológica entre necessidade e satisfação: segundo Bauman (1999, p. 90), "a promessa e a esperança de satisfação precedem a necessidade que se promete satisfazer e serão sempre mais intensas e atraentes que as necessidades efetivas". Consequentemente, mesmo que um produto recém-adquirido corresponda, de início, às expectativas que sobre ele recaíam no que diz respeito à satisfação de certas necessidades, basta que novas promessas de satisfação surjam para que aquele produto seja percebido como obsoleto. Essa situação só é possível porque novos produtos surgem no mercado a todo o momento, desempenhando melhor as funções que o produto anterior se propunha a realizar, ou mesmo sendo capaz de cumprir novas funções, fazendo surgir, dessa forma, novas necessidades que fomentam o anseio por satisfação. Nesse sentido, o consumidor entra num jogo no qual o mais importante é "não tanto a avidez de adquirir, de possuir, não o acúmulo de riqueza no seu sentido material, palpável, mas a excitação de uma sensação nova, ainda não experimentada" (BAUMAN, 1999, p. 91).

Pelo que foi exposto, é possível se verificar que as mercadorias postas à venda já saem das lojas com prazo de validade estipulado, sendo feitas para o consumo imediato. De acordo com Bauman (1999), o que essa lógica econômica busca é fazer com que a satisfação do consumidor seja instantânea, e isso num duplo sentido: por um lado, os bens consumidos visam satisfação imediata, sem a necessidade do aprendizado de quaisquer habilidades ou extensos fundamentos; e, por outro, a satisfação deve terminar no momento em que o tempo necessário para o consumo tiver terminado. Almeja-se, com isso, que o sujeito abra espaço à aquisição de um novo produto, reiniciando todo o ciclo. Nesse sentido, para utilizar 
uma expressão de Lipovetsky (2009), podemos dizer que o consumismo contemporâneo conduz o sujeito ao "império do efêmero".

Inserido nesse ciclo vicioso, o sujeito se encontra constantemente insatisfeito, ou, no máximo, experimentando momentos de curta satisfação. Isso é viver numa sociedade de consumo, onde a satisfação dos sujeitos não é mais a meta daqueles que oferecem insistentemente mais e mais produtos espetaculares, mas sim fomentar o crescimento, em volume e intensidade, dos desejos, que, por sua vez, levarão os sujeitos a consumirem cada vez mais. Nos termos baudrillardianos, a ampliação do consumo é o contraponto do ritmo acelerado da produção de bens; essa é a marca estrutural da sociedade de consumo que tem por base a própria produtividade industrial com sua propensão à abundância.

Atentando novamente para as características da cidade imaginária de Leônia construída por Calvino (2005) percebemos que essa, como toda sociedade de orientação consumista, quanto mais se supera na arte de fabricar novas mercadorias, tanto mais se depara constantemente com a necessidade de se desfazer dos antigos produtos para garantir espaço àquilo que é novidade. De acordo com Baudrillard (1995, p. 43), "a sociedade de consumo precisa dos seus objetos para existir e sente sobretudo necessidade de os destruir". Tendo em vista que, como ressalta Bauman (2008, p. 52), "a menos que complementado pelo impulso de se desfazer e se descartar, o impulso da mera aquisição e posse armazenaria problemas para o futuro": seria uma carga de quinquilharias pesada demais para se carregar, impedindo a mobilidade necessária para uma vida marcada pela flexibilidade da experiência. Por tal motivo, a alternativa crucial para a produção é a destruição final de suas criações.

A descrição realizada por Calvino (2005, p. 105) acerca de sua cidade imaginária nos fornece uma imagem sugestiva dessa realidade: "nas calçadas, envoltos em límpidos sacos plásticos, os restos da Leônia de ontem aguardam a carroça do lixeiro". Prosseguindo sua descrição aquele romancista acrescenta: "mais do que pelas coisas que todos os dias são fabricadas vendidas compradas, a opulência de Leônia se mede pelas coisas que todos os dias são jogadas fora para dar lugar às novas". Ao traçar essas características de sua cidade imaginária, Calvino nos leva a questionar "se a verdadeira paixão de Leônia é de fato, como dizem, o prazer das coisas novas e diferentes, e não o ato de expelir, de afastar de si, expurgar uma impureza recorrente".

Tal situação tem como principal consequência um aumento exponencial da produção de resíduos, fazendo com que Leônia fique cercada por montanhas crescentes de refugo. Assim como acontece com essa cidade ficcional, um imenso volume de resíduos tem envolvido as nossas grandes cidades. Alguns dados nos dão uma ideia da dimensão desse problema: em 2010, estimava-se que a produção de resíduos sólidos urbanos no mundo fosse aproximadamente de 2 bilhões de toneladas por ano (UNEP, 2015). No que diz respeito 
ao Brasil, a produção de resíduos urbanos chegou em 2014 à marca de 78,6 milhões de toneladas. Nesse contexto, em média, cada brasileiro produziu pouco mais de $387 \mathrm{~kg}$ de resíduos durante o ano (ABRELPE, 2015).

Tamanha quantidade de resíduos gerada por nossas sociedades consumistas deixa evidente, nas palavras de Bauman (2005, p. 38), que "o refugo é o segredo sombrio e vergonhoso de toda a produção". Рara os consumistas, os resíduos, por se constituírem em coisas inutilizadas, só ocupam espaço e tornam sujos os ambientes, por isso são encarados como algo ameaçador, já que sua presença macula a limpidez da vida cotidiana dos consumistas. Enquanto uma iminente ameaça, os objetos considerados lixo são afastados, enviados para locais muito distantes dos espaços de vivência. Com isso, de acordo com Bauman (2005), os resíduos se tornam ao mesmo tempo invisiveis, precisamente porque os sujeitos desviam o olhar em relação a eles, e inimagináveis, porque eles os extirparam de seus pensamentos.

Na cidade imaginária de Leônia esse intenso desejo por livrar-se dos resíduos se torna evidente através da importância dada ao trabalho desempenhado pelos lixeiros na limpeza da cidade. Esse é um rito extremamente silencioso justamente porque, "uma vez que as coisas são jogadas fora, ninguém mais quer pensar nelas" (CALVINO, 2005, p. 105). E mais, "ninguém se pergunta para onde os lixeiros levam os seus carregamentos: para fora da cidade, sem dúvida" (p. 106). É para os seus limites que as grandes cidades enviam toda sua produção de resíduos. No caso do Brasil, observando a destinação final dos resíduos urbanos, vemos que em 2008 os vazadouros a céu aberto ("lixões") estavam presentes como locais de despejo dos resíduos sólidos em 50,8\% dos municípios brasileiros; já os aterros, controlado e sanitário, correspondiam, juntos, a 50,2\% (IBGE, 2010, p. 60).

Segundo a descrição de Calvino (2005), devido ao constante e crescente acúmulo de objetos descartados nos limites de Leônia, tal área não consegue dar conta desse amontoado de resíduos, os quais passam a invadir a cidade. Acostumados ao cheiro da novidade sempre presente no seu dia a dia, os leonianos passam a ser perturbados pelo odor fétido das montanhas de lixo por eles mesmos produzidas. "Quando isso acontece, é difícil para eles desviar os olhos", são obrigados a "olhar, cheios de preocupação, medo e tremor", para aquelas montanhas, "e se horrorizar com essa visão" (BAUMAN, 2005, p. 8). O que antes podia ser ocultado (disfarçado) pelo distanciamento, agora começou a evidenciar-se em sua

\footnotetext{
${ }^{5}$ Os vazadouros são locais onde os resíduos são dispostos, no seu estado bruto, em terrenos a céu aberto, sem qualquer cuidado ou técnica, ou seja, "caracterizando-se pela falta de medidas de proteção ao meio ambiente e à saúde pública" (ABRELPE, 2009, p. 178). Já em relação aos aterros controlados e sanitários, temos que os primeiros se referem às áreas nas quais os resíduos, mesmo que dispostos sobre o solo, são cobertos com camadas de terra, porém sem que outros procedimentos sejam realizados para garantir uma efetiva proteção ao meio ambiente e à saúde pública. Diferentemente, aos segundos "são aplicados critérios de engenharia e normas operacionais especiais para confinar esses resíduos com segurança, do ponto de vista de controle da poluição ambiental e proteção à saúde pública" (ABRELPE, 2005, p. 72).
} 
grandeza. Ou, para utilizar outra metáfora, a quantidade de sujeira excedeu os limites do tapete, embaixo do qual normalmente era acumulada.

Os habitantes de Leônia, assim como os das nossas grandes cidades, se veem diante de um fato horripilante: as montanhas de lixo as quais "desejam tão avidamente se desvencilhar mostram-se relutantes em se degradar, deteriorar e decompor por si mesmas" (BAUMAN, 2005, p. 8). De que maneira é possível lidar com esse incômodo? Como extensão da produção industrial de mercadorias, surge o setor de tratamento de resíduos: investimentos são destinados à criação e ao desenvolvimento de tecnologias voltadas ao trato dos diversos tipos de resíduos. Assim, além dos vazadouros e aterros, os resíduos começam a ter outras possibilidades de destinação, tais como, compostagem, incineração e reciclagem ${ }^{6}$.

Com os resultados alcançados a partir de tais investimentos, verificou-se que, além dos benefícios ecológicos, a reintrodução dos materiais descartados no sistema produtivo se mostrou altamente promissora em termos de ganhos do capital global (CALDERONI, 2003). Segundo dados do Panorama dos Resíduos Sólidos no Brasil de 2014, os processos de reciclagem no país têm crescido significativamente. Nesse contexto, vale ressaltar-se que em relação a alguns tipos de materiais recicláveis os índices nacionais de reaproveitamento de resíduos se encontram entre os mais elevados do mundo: as latas de alumínio apresentam o índice mais elevado, atingindo a marca de 97,9\% de reinserção; o plástico tipo PET também alcançou um percentual bastante significativo, 58,9\%; já a reciclagem de papel ficou em torno de 45,7\% (ABRELPE, 2015).

A indústria da reciclagem, em seu processo de coleta e seleção de refugo apto ao reaproveitamento conta com um batalhão de pessoas, muitas vezes não reconhecidas nem devidamente valorizadas, provindas de um segmento social marginalizado pelo mercado de trabalho formal e que retiram dos materiais recolhidos nos vazadouros e/ou aterros a renda que thes garante a sobrevivência. Referimo-nos aqui aos catadores. Para a sociedade de consumo, apesar de incômoda, a presença dos catadores é de suma importância à estabilidade do sistema produtivo, tendo em vista que são eles que dão conta do refugo gerado por ela. Assim como para os habitantes da Leônia de Calvino, os consumidores do topo de nossa estrutura social capitalista precisam de pessoas "do tipo que não evitará tocar e manusear o que já foi destinado ao monte de dejetos", tendo em vista que eles, voltados

\footnotetext{
${ }^{6}$ A compostagem é um método de tratamento de resíduos, especificamente os materiais orgânicos, com a finalidade de produzir compostos passíveis de aproveitamento nas práticas agrícolas. No que concerne à incineração, essa consiste num processo de queima de resíduos, em especial aqueles provenientes do setor de saúde, contaminados biologicamente e/ou quimicamente, visando transformá-los em material estável e inofensivo à saúde pública. A reciclagem, método mais comum de tratamento de resíduos, refere-se a um processo de transformação através do qual se alteram as propriedades físicas, químicas, físico-químicas ou biológicas dos resíduos para que esses sejam utilizados como matéria-prima na manufatura de novos produtos (ABRELPE, 2009).
} 
unicamente à obtenção do prazer proveniente do consumo, não se dispõem a realizar o trabalho sofrível dos catadores (BAUMAN, 2005, p. 76).

Dizendo isso, estamos evidenciando a forma como nosso sistema capitalista mantém o mundo num equilíbrio que lhe convém: ao grande excedente de pessoas excluídas das categorias profissionais desrespeitadas, destituídas de meios de subsistência - e que, por isso, são incapazes de viver uma vida de consumo -, ou, em outras palavras, ao refugo humano ${ }^{7}$ de nossas sociedades, aquele sistema the destina, dentre outros subempregos que o considera apto a desempenhar, o posto de manejador do refugo material produzido por aqueles que têm o privilégio de consumir ostensivamente. Como sintetiza Bauman, de maneira magistral,

\begin{abstract}
"As pessoas cujas formas de subsistência ortodoxas e forçosamente desvalorizadas já foram marcadas para a destruição, e elas próprias assinaladas como refugo removível, não podem optar. Em seus sonhos noturnos podem moldar-se à semelhança dos consumidores, mas é a sobrevivência física, e não a orgia consumista, que thes ocupa os dias. Está montado o palco para o encontro dos dejetos humanos com as sobras das orgias consumistas - de fato, parecem ter sido feitos uns para os outros..." (BAUMAN, 2005, p. 76-77).
\end{abstract}

\title{
CATADOR: UM OFÍCIO RELEGADO À INVISIBILIDADE
}

À periferia das cidades são banidos não apenas os resíduos, mas também as pessoas que não fazem parte do seleto grupo de consumidores ostensivos de nossas sociedades capitalistas. Em ambos os casos a intenção é a mesma: busca-se - mesmo que em vão - levar à invisibilidade qualquer coisa que possa desvirtuar a imagem de ordem, limpeza e progresso da tão venerada metrópole moderna. Mais que isso, ao relegar às regiões periféricas tanto os resíduos quanto as pessoas que vivem em situação de miséria, as classes dominantes de nossas sociedades deixam evidente a forma como encaram aqueles sujeitos, a saber, os veem enquanto refugo humano. Estando nessa condição, não é de se estranhar que tais sujeitos tenham encontrado na catação dos resíduos que os circundam um dos poucos meios possíveis à sua sobrevivência - já que ser catador não é uma escolha, mas imposição de um

\footnotetext{
${ }^{7}$ De acordo com Bauman (2005, p. 12), "a produção de 'refugo humano', ou, mais propriamente, de seres humanos refugados (os 'excessivos' e 'redundantes', ou seja, os que não puderam ou não quiseram ser reconhecidos ou obter permissão para ficar), é um produto inevitável da modernização, e um acompanhante inseparável da modernidade. É um inescapável efeito colateral da construção da ordem (cada ordem define algumas parcelas da população como 'deslocadas', 'inaptas' ou 'indesejáveis') e do progresso econômico (que não pode ocorrer sem degradar e desvalorizar os modos anteriormente efetivos de 'ganhar a vida' e que, portanto, não consegue senão privar seus praticantes dos meios de subsistência)". A esses dois processos geradores de "refugo humano", Bauman acrescenta mais um, a saber, a globalização: "a expansão global da forma de vida moderna liberou e pôs em movimento quantidades enormes e crescentes de seres humanos destituídos de formas e meios de sobrevivência" (p. 14). Assim, "os refugiados, os deslocados, as pessoas em busca de asilo, os migrantes, os sans papiers constituem o refugo da globalização" ( $p$. 76).
} 
sistema excludente. Essa conjuntura nos leva a seguinte realidade: os "lixões" urbanos representam não apenas o ambiente de trabalho, mas a moradia de uma parcela imprecisa da população.

Visando compor, mesmo que apenas de forma aproximada, uma imagem da condição de vida dos catadores de resíduos que circundam nossas cidades, será desenvolvida nas próximas linhas uma análise descritiva da situação laboral de catadores que atuavam em dois depósitos de resíduos outrora situados na região metropolitana do Rio de Janeiro: o primeiro é o Vazadouro de Itaoca, município de São Gonçalo; o segundo é o Aterro Sanitário de Jardim Gramacho, o qual se localizava no município de Duque de Caxias. Como expomos na introdução do presente trabalho, tais localidades foram, respectivamente, objetos dos documentários Boca de Lixo (BL) e Lixo Extraordinário (LE), os quais nos forneceram todo um complexo de imagens e falas de sujeitos que se constituíram na matéria-prima para a nossa análise.

Um primeiro dado que tais documentários evidenciam: as pessoas que vivem na condição de catadores desempenham um trabalho com alto grau de insalubridade. No entanto, mesmo que se deem conta dessa realidade, os catadores não têm outra opção, pois são pressionados pela urgência da sobrevivência. Em linhas gerais, dentre os principais riscos aos quais estão expostas essas pessoas, encontram-se: ferimentos, causados por objetos cortantes - pedaços de vidro, metais pontiagudos...; intoxicação, devido à exposição a materiais orgânicos em processo de decomposição e a resíduos provenientes do setor industrial - equipamentos eletroeletrônicos, pilhas, baterias, lâmpadas fluorescentes... - e dos serviços de saúde - restos de medicamentos, agulhas e seringas usadas... Por meio da fala dos catadores, percebemos que esses têm consciência de que estão expostos a tais riscos. Enock, de 70 anos, enfatiza o perigo de se trabalhar como catador de resíduos, tendo em vista que, como ele mesmo já pode observar, muitas pessoas expostas aos "lixões" ficam doentes; outra catadora, não identificada, aponta para o constante perigo de contaminação ao qual está exposta, principalmente devido aos resíduos hospitalares. "Agora tá muito perigo com negócio de agulha infectada", ela destaca, mostrando o ferimento causado, no dia anterior, por uma picada de agulha (BL).

Fora a exposição a tantos fatores de risco à saúde no processo da catação de resíduos, os catadores ainda têm de enfrentar uma jornada diária de trabalho demasiadamente longa e desgastante, que inicia todas as manhãs e, por vezes, só termina ao anoitecer. A catação é feita de maneira individual: com enxadas os catadores reviram os resíduos em busca do que acreditam poder reaproveitar. Dessa forma, vão recolhendo o que encontram em enormes balaios ou sacos, que, quando cheios, são transportados em suas cabeças. Todo material que conseguem coletar é vendido, por preços abaixo do valor de mercado, aos intermediários das indústrias de reciclagem de materiais. 
Como dissemos anteriormente, realizar esse trabalho tão sofrível não é uma questão de opção. Normalmente, os catadores de resíduos são desempregados e com baixo nível de formação escolar e profissional. Ao não serem absorvidos pelo mercado de trabalho, acabam tendo como única possibilidade laboral a catação de resíduos. Enock, o catador anteriormente citado, confessa que já trabalhou como pedreiro, lavrador e até como seringueiro, mas, nesse momento, só tem o trabalho com resíduos como opção; na fala de outra catadora percebemos o grau de insatisfação com a atividade desempenhada. Ela diz, acerca do trabalho como catadora, que "bom não é", mas pondera ser o "lixão" a principal fonte de seu sustento, tendo em vista que, se "não tem outro [trabalho], tem de pegar esse mesmo", pois "tá ruim de serviço lá pra fora". Quando questionada sobre os locais nos quais já havia trabalhado, a catadora recorda com saudosismo as boas condições do serviço desenvolvido em casas de família: "não tem comparação", ela enfatiza, "porque trabalha limpa, a gente come. Aqui [no 'lixão'] a gente não almoça, só janta" (BL).

Os "lixões" se tornaram para muitas pessoas a única realidade que conhecem. Algumas viveram boa parte de suas vidas neles, exercendo a função de catador: Nirinha é um exemplo, pois trabalha há mais de 15 anos como catadora de resíduos. Outras pessoas nasceram e cresceram já nessa condição: uma catadora não identificada deixou evidente que pelo menos há duas gerações sua família vem vivendo da catação: "minha mãe criou nós todo aqui [no 'lixão'], graças a Deus. Minha mãe tem dez filho, todos dez foi criado com a comida daqui, o dinheiro daqui... Desde os sete ano que eu trabalho no lixo" (BL).

Em ambos os documentários aqui analisados percebe-se a existência de fortes relações amicais e de cumplicidade entre os catadores. Isso se explica pelo fato de partilharem as mesmas difíceis condições de existência, o que os leva a estabelecer laços de solidariedade que thes possibilitam certo sentimento de segurança num contexto tão inseguro: os catadores têm a certeza de que, por pior que seja a situação, sempre podem se apoiar uns nos outros. Há um forte sentimento de fraternidade entre eles: "todo mundo é amigo", diz a catadora Lúcia, "quando eu tou lá no lixo... eu grito, eu falo, eu mexo com um, mexo com outro, eles me jogam coisa, eu jogo coisa neles" (BL). Tais relações amicais enriquecem as poucas horas de descanso e lazer que os catadores têm nos intervalos entre a chegada de um e outro caminhão de resíduos: alguns se divertem com o jogo de cartas; outros jogam futebol se utilizando de uma bola improvisada que fora encontrada em meio ao refugo; crianças brincam com bolinhas de gude; com um rádio velho, alguns escutam músicas; enquanto outros folheiam restos de jornais e revistas, mesmo que não saibam ler.

Por tudo que foi dito até o momento podemos ter uma pequena noção da degradante situação do catador de resíduos. Além de suportarem as péssimas condições de trabalho, os sujeitos que vivem da catação de resíduos ainda sofrem preconceito e discriminação por parte dos grupos sociais que possuem melhores condições de vida. 
Comumente, os catadores são tratados como portadores de doenças contagiosas, ladrões, dependentes químicos... Em suma, são menosprezados e estigmatizados por causa da atividade que desempenham. Nessa situação, a baixa autoestima demonstrada pelos catadores é uma consequência já esperada: eles cobrem seus rostos com vergonha da situação na qual se encontram. Na fala do catador Loloi revela-se a indignação que esse sente diante do preconceito que constantemente sofre: "todo mundo aqui tá trabalhando, não tem ninguém roubando aqui dentro [do 'lixão']... Todo mundo trabalha, ninguém rouba. Se tivesse nego roubando aqui dentro, ninguém ia trabalhar. Todo mundo tá aqui porque depende..." (BL). Discorrendo sobre suas experiências, a catadora Magna relata uma situação humilhante pela qual passou: "a gente chegava no ônibus, o pessoal ficava assim [incomodado com nosso cheiro]". Frente a esse desprezo, ela enfatizou sua honradez: "eu cheguei ao ponto de dizer para uma senhora: 'olha, vem cá, eu tou fedendo? Tá sentindo mau-cheiro? É porque eu estava trabalhando lá no lixão. É melhor do que se eu estivesse lá em Copacabana rodando bolsinha... Tou fedendo, mas chegar em casa, toma um banho e fica melhor" (LE).

Uma mudança de vida é o que todos os catadores almejam. Sabem que no momento presente o trabalho com os resíduos é sua única possibilidade, mas isso não os impede de projetar, de planejar um futuro melhor, tanto para si quanto para seus familiares. Essa esperança pode ser claramente visualizada no seguinte depoimento do catador Zumbi: "nós tem que pensar também no futuro... Porque é aquele negócio né: eu não quero que meu filho seja catador, apesar se for, vou ser super orgulhoso. Mas eu prefiro que ele seja o que? Um advogado, para representar a categoria de catador... Uma médica para cuidar do catador numa cooperativa..." (LE).

Ao projetar o crescimento profissional do filho visando, em última instância, os interesses dos catadores enquanto categoria trabalhista, Zumbi demonstra sua busca pelo reconhecimento e legitimidade sociais de sua atividade. Essa é uma luta constante dos catadores que, inclusive, já se encontram congregados no Movimento Nacional dos Catadores de Materiais Recicláveis - MNCR ${ }^{8}$. Segundo essa organização, "o catador sempre foi visto como um sujeito excluído socialmente". Contudo, presta um serviço tão importante à sociedade, "mesmo sem dela receber o reconhecimento, nem do poder público receber o pagamento devido por tal trabalho" ${ }^{9}$. Nesse sentido, nos lembra Bourdieu que

\footnotetext{
${ }^{8}$ O Movimento Nacional dos Catadores de Materiais Recicláveis (MNCR) surgiu em 1999, durante o $1^{\circ}$ Encontro Nacional de Catadores de Papel, mas só se efetivou na arena política em 2001 quando do $1^{\circ}$ Congresso Nacional dos Catadores de Materiais Recicláveis. Nesses mais de 16 anos de existência tal movimento vem trabalhando em prol do reconhecimento, da inclusão social, da legitimidade profissional e da melhoria das condições de trabalho das pessoas que vivem da catação de resíduos. Para mais informações sobre o MNCR cf. http://www.mncr.org.br/.
}

${ }^{9}$ Cf. CICLO da Cadeia Produtiva de Reciclagem. In. MNCR - Movimento Nacional dos Catadores de Materiais Recicláveis, São Paulo, 26 mar. 2008. Disponível em: 
"Não existe pior esbulho, pior privação, talvez, do que a dos derrotados na luta simbólica pelo reconhecimento, pelo acesso a um ser social socialmente reconhecido, ou seja, numa palavra, à humanidade. Essa luta [...] é uma concorrência em torno de um poder que só pode ser obtido junto a outros concorrentes pelo mesmo poder, um poder sobre os outros que deriva sua existência dos outros, de seu olhar, de sua percepção e de sua apreciação." (BOURDIEU, 2001, p. 295).

Noutras palavras, só é possível ao catador de resíduos almejar uma posição de respeito no âmbito social a partir do momento em que consegue conquistar a atenção daqueles em relação aos quais deseja reconhecimento. Ao ser percebido em sua existência, o catador pode erguer a voz e, de fato, ser ouvido. Nesse sentido, é de fundamental importância o papel das cooperativas, associações e movimentos sociais em prol daqueles que sobrevivem da catação de resíduos. Pois é principalmente através da união de suas forças que os catadores, além de aumentarem sua autoestima, podem lutar por melhorias nas suas condições de trabalho e de vida.

\section{O FIM É UM NOVO COMEÇO: AS METAMORFOSES DO LIXO}

De início, realizamos uma breve discussão sobre como as nossas sociedades consumistas, encerradas nos muros das metrópoles modernas, têm originado, devido ao seu assíduo investimento em produtos cuja utilidade se mostra cada vez mais efêmera, um imenso acúmulo de resíduos. Num primeiro momento, as mercadorias que saem das lojas visam saciar determinadas necessidades; no entanto, ao passo que se tornam obsoletas frente aos novos produtos que chegam ao mercado, elas passam a figurar como algo inútil, desnecessário, passível de ser descartado; a partir desse instante, as mercadorias se transformam em resíduos.

É importante se perceber, nesse contexto, que a utilidade não é um aspecto natural de um objeto, mas uma qualidade que the é atribuída pelos sujeitos que dele se apropriam. Da mesma forma, um objeto só é rejeitado ou tido como inútil a partir do instante em que os sujeitos the imputam tal inutilidade. Em outras palavras, queremos dizer que o lixo, enquanto coisa desprovida de serventia, só pode ser uma construção subjetiva, tendo em vista que, em termos naturais, ele não existe propriamente. Como expressou o filósofo Lucrécio (1962, p. 60), "não é destruído inteiramente nada do que parece destruir-se, porque a natureza refaz os corpos a partir uns dos outros e não deixa que nenhum se crie senão pela ajuda da morte de algum outro". Bauman (2005, p. 32) corrobora com tal perspectiva ao afirmar, citando Mary Douglas, que "nenhum objeto é 'refugo' por suas qualidades intrínsecas, e nenhum pode tornar-se refugo mediante sua lógica interna". Nesse sentido, ele prossegue afirmando que "é recebendo o papel de refugo nos projetos humanos que os objetos materiais, sejam

http://www.mncr.org.br/biblioteca/formacao-e-conjuntura/ciclo-da-cadeia-produtiva-de-reciclagem. Acesso em 26 jun. 2016. 
eles humanos ou inumanos, adquirem todas as qualidades misteriosas, aterrorizantes, assustadoras e repulsivas" que os conduzem ao distanciamento em relação aos sujeitos que um dia os consumiram.

É precisamente por ser resultado de uma construção subjetiva, e não uma condição decorrente da lógica intrínseca a um objeto, que aquilo que é considerado lixo por alguns, ao chegar às mãos do catador, pode ser ressignificado (reciclado) e tornar-se novamente um elemento dotado de valor, isto é, que tem uma utilidade - seja desempenhando sua função de origem, seja cumprindo uma nova funcionalidade. Isso explica também o fato de que nas mãos de um artista aquilo que por outros era considerado lixo pode mesmo se tornar matéria-prima à constituição de uma valorosa obra-de-arte.

Com essa sucinta introdução, almejamos chamar a atenção às variadas formas de percepção acerca dos resíduos e, com isso, apontar alguns modos de apropriação que the são possíveis. Nosso foco recairá, nas próximas linhas, sobre o tratamento dado aos resíduos sólidos urbanos tanto pelo catador quanto pelo artista plástico, enfatizando que o ponto de intersecção entre essas duas categorias encontra-se no fato de que ambas transformam aqueles resíduos da condição de material desprezado (lixo) à de objeto reutilizável/revalorizado. Os documentários supracitados nos fornecerão os exemplos dessas duas formas de percepção/apropriação no que concerne aos resíduos sólidos urbanos.

\section{EM PROL DA SOBREVIVÊNCIA OU A RELAÇÃO DO CATADOR COM OS RESÍDUOS}

As imagens dos "lixões", realizadas pelos dois documentários em questão, evidenciam que o momento crucial para os sujeitos que vivem da catação é a chegada dos caminhões de resíduos. São esses que trazem a matéria necessária à sobrevivência daqueles sujeitos. Na fala da catadora Lúcia tal situação é evidenciada: "a gente precisa daquela lixeira porque tem uma comida de porco, tem uma roupa, a gente acha as roupas boa, acha calçados bons... Vem coisas boa. Que o que não serve, as vezes não serve lá para o rico, serve para o pobre. E, pra gente, aquilo ali é útil. Tem muita coisa útil ali" (BL).

Diante de um depoimento como esse, não é de se estranhar a mobilização gerada entre os catadores todas as vezes que acontece um descarregamento de resíduos: os sujeitos avançam sobre as montanhas formadas de objetos descartados, revirando-as até encontrar materiais que acreditam poder reaproveitar ou vender. Dessa forma eles dão novo valor, em dois sentidos, aos restos desprezados:

1) Quando restituem suas funções originais: as residências dos catadores acabam sendo mobiliadas e ornamentadas com os objetos encontrados no lixo - sofás, pôsteres da cultura 
pop, relógios de parede, livros $^{10}$...; dos materiais outrora inutilizados, eles ainda recuperam roupas, calçados e outros adornos, que passam a compor a sua vestimenta; e, por fim, recolhem restos de alimentos que, se ainda passíveis de consumo humano, são aproveitados em suas próprias refeições, ou, caso contrário, são destinados ao mantimento dos animais;

2) Quando thes designam outras funções: tomando-os como fonte de renda, os catadores selecionam, durante o processo de coleta, os resíduos que podem vender, enquanto matériaprima, para a indústria da reciclagem.

Sobre essa última forma de apropriação, cabe esclarecer que são considerados recicláveis os resíduos que despertam certos interesses comerciais, ou seja, que têm mercado e/ou mobilizam processos que viabilizam sua transformação industrial ${ }^{11}$. Nesse sentido, os resíduos passaram a ser classificados segundo sua origem - doméstica, comercial, industrial, hospitalar, etc. (PINTO, 1979) - e separados segundo sua natureza - papel, plástico, vidro, metal, orgânico, etc. - com a finalidade de otimizar o processo de seleção dos materiais que o interesse mercantil aponta enquanto aptos à reciclagem.

Então, é com base nessa classificação que os catadores recolhem os resíduos, vendendo-os aos intermediários das indústrias do setor de reciclagem. Segundo informações expostas no documentário Lixo Extraordinário, podemos constatar essa orientação na atividade da catação: "os catadores recolhem o que a indústria tá pedindo", ou seja, trabalham "de acordo com a demanda", informa Lúcio Alves, administrador do aterro sanitário de Gramacho no período em que fora produzido aquele documentário. O volume aproximado de material reciclável que era coletado nesse aterro girava em torno de 200 toneladas por dia - quantidade representativa da produção de resíduos referente a uma cidade de 400 mil habitantes (LE).

\section{EM PROL DA CONTEMPLAÇÃO OU A RELAÇÃO DO ARTISTA PLÁSTICO COM OS RESÍDUOS}

Ao interpretarmos a postura artística de Vik Muniz, sensível artista que buscou evidenciar a extraordinariedade do que alguns consideram lixo, poderíamos dizer que a obrade-arte é, dentre outras possibilidades de definição, produto e produtora de transformações. É produto, pois surge de um processo no qual o artista modela uma matéria bruta medíocre,

\footnotetext{
${ }^{10}$ Em um dado momento do documentário Lixo Extraordinário, o catador Zumbi relata que durante a catação de resíduos é comum encontrar livros ainda em bom estado para o uso. Em vez de destinálos à reciclagem de papéis, ele os reserva com o intuito de compor uma biblioteca comunitária para os habitantes da favela do Jardim Gramacho. Esse sonho, como veremos mais adiante, logo se realizará com a ajuda de financiamento provindo da venda de obras do artista plástico Vik Muniz.

${ }^{11}$ Para mais informações sobre os materiais considerados recicláveis Cf. Coleta Seletiva - O que é Reciclável?. In. Lixo.com.br, Rio de Janeiro. Disponível em: http://www.lixo.com.br/index.php?option=com_content\&task=view\&id=136\&ltemid=243. Acesso em 10 set. 2011; e Maria Teresa C. Mansor, 2010.
} 
transformando-a em algo significativo, dotado de valor. No entanto, quando finalizada, a obra-de-arte pode ser capaz de transformar, subjetivamente, aqueles que a contemplam. Ela comunica certas experiências ao mesmo tempo em que promove outras novas. A mágica da arte está, em suma, na sua capacidade de possibilitar o encontro de experiências. O documentário Lixo Extraordinário trata, justamente, desses dois momentos de transformação, os quais serão empiricamente descritos nas próximas linhas.

O trabalho de Vik Muniz, que pudemos acompanhar através da produção fílmica citada, consiste basicamente em incorporar certos materiais, tais como areia, açúcar, fios, arame, chocolate, entre outros, no processo fotográfico, compondo imagens de situações que se relacionam com tais materiais. Os resíduos sólidos urbanos foram, num dado momento, mais um elemento do qual se serviu Muniz para composição de sua arte. Essa situação nos permitiu perceber mais uma forma possível de apropriação dos resíduos gerados por nossas sociedades consumistas.

Quando se propôs a utilizar-se de resíduos como base para elaboração de suas fotografias, Muniz tinha uma ideia em mente:

O que realmente quero fazer é ser capaz de mudar a vida de um grupo de pessoas com o mesmo material que elas lidam todo dia. Não um material qualquer. A ideia para a próxima série é trabalhar com o lixo. Quando falamos de transformação, esta é a matéria da arte, transformar material em ideia... Este é o começo de uma ideia. Só preciso do material. E tenho de ir em busca de uma imagem. (LE)

Para realização desse projeto, Muniz se deslocou para o aterro sanitário de Jardim Gramacho, visando observar o dia-a-dia das pessoas que sobrevivem da catação de resíduos: "a iconografia irá se desenvolver de minha interação com elas [as pessoas que vivem da catação]. Quero ver o que é importante para elas. O que elas acham que faz uma grande imagem. O que elas querem mostrar", diz o artista plástico (LE). A intenção era fotografar os catadores em sua vivência com os resíduos, para utilizar logo em seguida as imagens capturadas como base sobre a qual seriam dispostos os variados tipos de refugo que se encontrassem naquela localidade, montando diversos mosaicos. Esses, por sua vez, seriam também fotografados. Ao final do processo, as imagens iniciais reaparecem transformadas: nelas podemos perceber, numa sensível combinação, a objetividade que circunda a experiência da catação de resíduos, por meio dos materiais físicos que a atravessam e a caracterizam, e a subjetividade dos sujeitos que vivenciam aquela experiência, através de suas expressões (ver fig. 1).

Fig. No 1: Processo de composição artística de uma das obras da coleção "Retratos do Lixo", de Vik Muniz ${ }^{12}$ :

\footnotetext{
${ }^{12}$ Imagens veiculadas por Vik Muniz Studio para divulgação do documentário Lixo Extraordinário.
} 


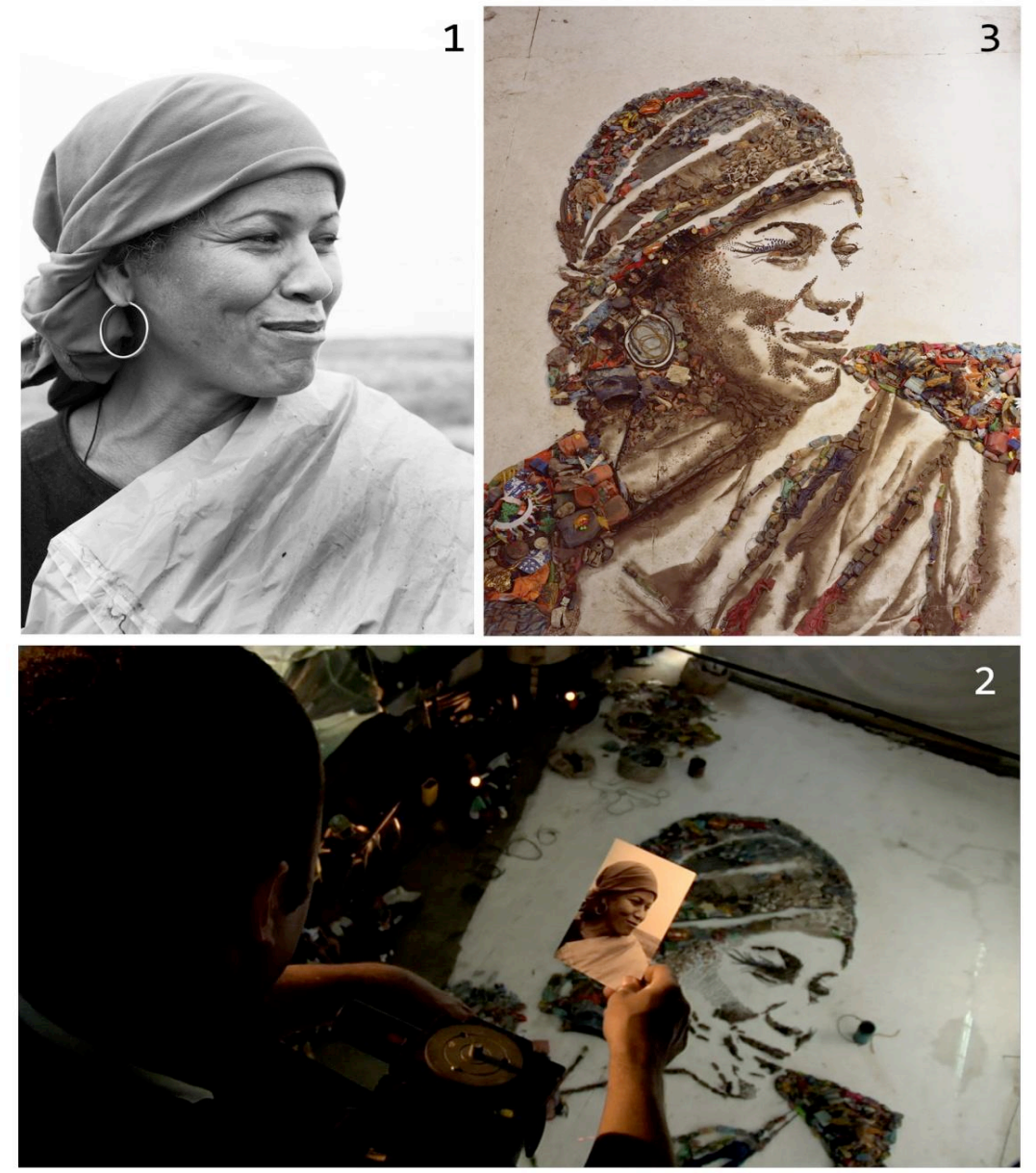

1) Realização da foto com a catadora Magna; 2) A partir da foto, compõese um mosaico tendo resíduos como matéria-prima; 3) Obra de arte realizada, sendo nomeada "The Gipsy Magna".

Além de terem sido os modelos fotográficos das imagens feitas por Muniz, os catadores também participaram do trabalho de composição dos mosaicos a serem fotografados. Dessa forma, eles foram inseridos no processo de criação artística como sujeitos ativos, tornando-se, de certa maneira, também artistas. Essa situação é bastante representativa, indicando, em última instância, que aos catadores foi devolvida a autoria de suas próprias representações e a possibilidade de relatarem, por si mesmos, suas próprias experiências. Percebe-se, dessa forma, que o trabalho artístico realizado por Muniz tinha uma proposta social intrínseca. Sobre isso, revela o artista plástico:

Minha experiência com a mistura de arte com projeto social é a principal coisa: tirar as pessoas, nem que seja por poucos minutos, do lugar onde elas estão e mostrar-lhes um outro mundo, um outro lugar. Mesmo que seja um lugar onde possam ver onde estão. Isso muda tudo. Seria uma experiência sobre como a arte pode mudar as pessoas, como também se ela consegue mudar. (LE)

Todo o dinheiro arrecadado com a venda da coleção de imagens, batizada por Muniz de "Retratos do Lixo", foi revertido para a melhoria das condições de vida dos catadores do Aterro Sanitário de Jardim Gramacho. As obras renderam mais de 250 mil dólares, os quais foram empregados tanto no processo de coleta de resíduos, com a aquisição de um 
caminhão e de equipamentos, como no desenvolvimento cultural daqueles que sobrevivem da catação de resíduos, através da inauguração de um centro de ensino e de uma biblioteca com 15 computadores.

\section{CONSIDERAÇÕES FINAIS}

Quando, no começo de nossa explanação, fizemos referência a Leônia - cidade imaginada por Calvino -, tínhamos em mente enfatizar dois aspectos característicos da vida urbana nas metrópoles contemporâneas: o consumismo e a crescente produção e acúmulo de resíduos. Em relação a esse segundo aspecto, verificamos que os consumidores da referida cidade imaginária tinham descartado tantos objetos que não podiam mais fazer de conta que a montanha de resíduos que crescia nos confins de Leônia não existia:

"[A montanha de resíduos,] quanto mais cresce em altura, maior é a ameaça de desmoronamento: basta que um vasilhame, um pneu velho, um garrafão de vinho se precipitem do lado de Leônia e uma avalanche de sapatos desemparelhados, calendários de anos decorridos e flores secas afunda a cidade no passado que em vão tentava repelir." (CALVINO, 2005, p. 106)

Os leonianos, mesmo que viessem a passar, de fato, por essa situação catastrófica de serem soterrados pelos seus próprios resíduos, não conseguiriam nunca apreender uma simples verdade: "os odiosos montes de lixo só poderiam não existir se, antes de mais nada, não tivessem sido feitos" por eles mesmos (BAUMAN, 2005, p. 9). Essa parece ser a sina de nossas sociedades consumistas. Tanto é que, diante do desesperador crescimento da produção de resíduos, a solução cogitada e implementada, ao invés de ser uma mudança comportamental no sentido de uma diminuição do consumo supérfluo, é antes um estrondoso investimento em ações e tecnologias voltadas à reciclagem.

De qualquer forma, mesmo que a solução encontrada tenha sido a de tratar os resíduos, alguém ainda teve de "sujar as mãos" com eles. Evidentemente, os nossos cidadãos consumistas não se prestaram a essa tarefa. Nesse momento, surge o sujeito catador, que, devido as suas parcas condições de entrar na esteira do consumismo, tem de sobreviver do refugo daqueles que podem consumir ostensivamente. Para a indústria da reciclagem, este é um casamento perfeito: o catador de mãos dadas com o material reciclável. Assim, chegamos as seguintes percepções acerca dos resíduos: se num primeiro momento o resíduo foi tomado pelos consumidores como lixo, algo inútil e desprezível, posteriormente, nas mãos do catador ele foi revalorizado, tornando-se fonte de subsistência.

Vimos que as pessoas que trabalham na catação, mesmo desempenhando um papel fundamental para a sociedade de consumidores, são por essa menosprezadas. Além de suportarem as péssimas condições de um trabalho não legitimado, ainda sofrem preconceito e discriminação. Elas são privadas dos meios essenciais ao exercício de uma cidadania plena, sendo relegadas à invisibilidade juntamente com os resíduos - isso porque ambos são 
percebidos enquanto "elementos" indesejados. Como mudar esse quadro? Como legitimar e com isso dignificar uma atividade que muitos consideram indigna? Como melhorar as condições de trabalho dos catadores? E, principalmente, como esses podem alcançar o reconhecimento social?

Parece-nos que o primeiro passo rumo à resolução desses problemas é retirar da condição de invisibilidade tanto os resíduos quanto os sujeitos que desses sobrevivem, os ressignificando a fim de mudar a perspectiva que a sociedade tem deles. Nesse sentido, a arte emerge como uma contribuição efetiva. Foi o que pudemos observar através do trabalho do artista plástico Vik Muniz.

Considerando que a arte mantém uma proximidade ontológica com o contexto do qual emerge, é sintomático que, numa sociedade que vem produzindo mais e mais toneladas de resíduos, esses tenham se tornado matéria-prima de um trabalho artístico: a grande obra "Retratos do Lixo" criada por Muniz é um exemplo majestoso da apropriação artística do refugo. Mais que isso, esse trabalho congrega numa mesma obra o refugo material e o refugo humano, retirando-lhes essa qualidade de refugo - ou seja, de elementos sem valor -, para restituir-lhes a sua dignidade, a sua importância, enfim, a sua existência.

Quando imergiu no "lixão" para começar o processo de composição de sua obra, Muniz foi questionado por um catador que lá se encontrava sobre o que era e qual a finalidade do trabalho que estava realizando. "A gente tá querendo criar um retrato do catador, porque o catador é uma pessoa, como o lixo que tá aqui, é uma pessoa que ninguém conhece", respondeu o artista. Compreendendo a importância daquela ação, o catador concluiu: "muito bem, então com tudo o que o senhor falou, no meu entender, isso é muito bom pra nós, porque isso leva o nosso reconhecimento, de nossa classe como catadores" (LE).

Por tudo que foi exposto até aqui, concluímos: se Leônia - vista enquanto uma alegoria das nossas sociedades consumistas - não quer deixar de consumir e, consequentemente, produzir resíduos e mais resíduos, então que busque conviver, sem preconceitos e discriminação, com o refugo de suas práticas consumistas e com aqueles que dele sobrevivem. Eis um primeiro passo para o reconhecimento e para a superação dos problemas postos. 


\section{REFERÊNCIAS}

ABRELPE - Associação Brasileira de Empresas de Limpeza Pública e Resíduos Especiais. Panorama de Resíduos Sólidos no Brasil 2004. São Paulo: ABRELPE, 2005.

Panorama de Resíduos Sólidos no Brasil 2008. São Paulo: ABRELPE, 2009.

Panorama de Resíduos Sólidos no Brasil 2014. São Paulo: ABRELPE, 2015.

BAUDRILLARD, Jean. A sociedade de consumo. Rio de Janeiro/Lisboa: Edição 70; Elfos, 1995.

BAUMAN, Zygmunt. Consumismo versus consumo. In. Vida para consumo: a transformação das pessoas em mercadoria. Rio de Janeiro: Jorge Zahar Ed., 2008, p. 37-69. . Turistas e vagabundos. In. BAUMAN, Zygmunt. Globalizaçã 0: as consequências humanas. Rio de Janeiro: Jorge Zahar Ed., 1999, p. 85-110.

. Vidas desperdiçadas. Rio de Janeiro: Jorge Zahar Ed., 2005.

BOCA de Lixo. Direção: Eduardo Coutinho. 1993. 1 DVD, 49 min, color.

BOURDIEU, Pierre. Meditações pascalianas. Rio de Janeiro: Bertrand Brasil, 2001.

BRASIL. Lei $n^{0}$ 12.305, de 2 de agosto de 2010. Institui a Política Nacional de Resíduos Sólidos. Disponível em: <http://www.planalto.gov.br/ccivil_03/_ato2007-2010/2010/lei/l12305.htm>. Acesso em: 02 nov. 2012.

CALDERONI, Sabetai. Os bilhões perdidos no Lixo. 4. ed. São Paulo: Humanitas FFLCH/USP, 2003.

CALVINO, Italo. As cidades contínuas 1. In. As cidades invisíveis. 2. ed. São Paulo: Companhia das Letras, 2005, p. 105-107.

CICLO da Cadeia Produtiva de Reciclagem. In. MNCR - Movimento Nacional dos Catadores de Materiais Recicláveis, São Paulo, 26 mar. 2008. Disponível em: http://www.mncr.org.br/biblioteca/formacao-e-conjuntura/ciclo-da-cadeia-produtiva-de-reciclagem. Acesso em 26 jun. 2016.

COLETA Seletiva - 0 que é Reciclável?. In. Lixo.com.br, Rio de Janeiro. Disponível em: http://www.lixo.com.br/index.php?option=com_content\&task=view\&id=136\&ltemid=243. Acesso em 10 set. 2011.

IBGE - Instituto Brasileiro de Geografia e Estatística. Pesquisa Nacional de Saneamento Básico 2008. Rio de Janeiro: IBGE, 2010.

LIPOVETSKY, Gilles. 0 império do efêmero: a moda e seu destino nas sociedades modernas. São Paulo: Companhia das Letras, 2009.

LIXO Extraordinário (Waste Land). Direção: Lucy Walker. 2011. 1 DVD, 99 min, color.

LUCRÉCIO CARO, Tito. Da Natureza. Rio de Janeiro/Porto Alegre/São Paulo: Globo, 1962. 
MANSOR, Maria Tereza Castilho et al. Resíduos Sólidos. São Paulo: SMA, 2010. (Cadernos de Educação Ambiental, 6).

MNCR - Movimento Nacional dos Catadores de Materiais Recicláveis, São Paulo. Disponível em: http://www.mncr.org.br/. Acesso em 10 set. 2011.

PINTO, Mario da Silva. A coleta e disposição do lixo no Brasil. Rio de Janeiro, Fundação Getúlio Vargas, 1979.

UNEP - United Nations Environment Programme. Global Waste Management Outlook. Nairobi: UNEP; ISWA, 2015.

Recebido em 28 de julho de 2018.

Aprovado em 06 de dezembro de 2018. 